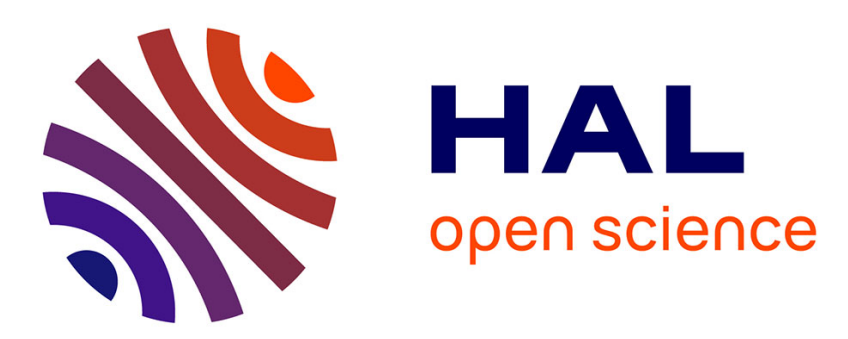

\title{
Light scattering from oil-water interfaces : measurements of low interfacial tensions
}

\author{
A. Pouchelon, J. Meunier, D. Langevin, A.M. Cazabat
}

\section{To cite this version:}

A. Pouchelon, J. Meunier, D. Langevin, A.M. Cazabat. Light scattering from oil-water interfaces: measurements of low interfacial tensions. Journal de Physique Lettres, 1980, 41 (10), pp.239-242. 10.1051/jphyslet:019800041010023900 . jpa-00231769

\section{HAL Id: jpa-00231769 https://hal.science/jpa-00231769}

Submitted on 1 Jan 1980

HAL is a multi-disciplinary open access archive for the deposit and dissemination of scientific research documents, whether they are published or not. The documents may come from teaching and research institutions in France or abroad, or from public or private research centers.
L'archive ouverte pluridisciplinaire HAL, est destinée au dépôt et à la diffusion de documents scientifiques de niveau recherche, publiés ou non, émanant des établissements d'enseignement et de recherche français ou étrangers, des laboratoires publics ou privés. 
LE JOURNAL DE PHYSIQUE-LETTRES

J. Physique - LETTRES 41 (1980) L-239 - L-242

15 mai 1980, page L-239

Classification

Physics Abstracts

$68.10-78.35-73.30$

\title{
Light scattering from oil-water interfaces : measurements of low interfacial tensions
}

\author{
A. Pouchelon, J. Meunier, D. Langevin and A. M. Cazabat \\ Laboratoire de Spectroscopie Hertzienne de l'E.N.S., \\ 24, rue Lhomond, 75231 Paris Cedex 05, France
}

(Reçu le 14 décembre 1979, accepté le 28 mars 1980)

Résumé. - L'étude du spectre de la lumière diffusée nous a permis de remonter aux tensions interfaciales dans les systèmes eau-huile. Les résultats sont relatifs à des mélanges eau salée-toluène-sulfate de dodécyl et de sodiumbutanol 1. Les tensions interfaciales mesurées les plus faibles sont de l'ordre de $10^{-3} \mathrm{dyn} . / \mathrm{cm}$. Mais cette technique doit pouvoir encore être applicable pour des valeurs de $10^{-5}$ à $10^{-6} \mathrm{dyn} . / \mathrm{cm}$. Les résultats ont été reliés à un certain nombre de propriétés volumiques des phases en présence : viscosité, conductivité électrique, coefficient de diffusion des espèces micellaires.

\begin{abstract}
Interfacial tension has been deduced from the spectrum of the light scattered by the interface. The results are relative to water-toluene-sodium dodecyl sulfate-butanol 1 mixtures. The lowest measured values are of the order of $10^{-3} \mathrm{dyn} . / \mathrm{cm}$. It is expected that measurements down to $10^{-5}-10^{-6} \mathrm{dyn} . / \mathrm{cm}$ will be possible with this technique. The results have been related to several properties of the bulk phases : viscosity, electrical conductivity, and diffusion coefficients of micellar species.
\end{abstract}

1. Introduction. - The oil-water interfaces of low interfacial tensions and microemulsions have recently attracted much interest, in relation to oil recovery problems [1]. The measurements of low interfacial tensions are usually done by the spinning drop technique, which sometimes presents some difficulties [2]. Another technique, well suited to low interfacial tension measurements, has been developed in our laboratory namely : the study of laser light inelastically scattered by spontaneous thermally excited capillary surface waves [3]. The advantage of the technique is to avoid perturbations of the liquid interface. Some preliminary measurements have already been reported [4].

We present here measurements on oil water systems separating into three-phases. In this case, the two interfaces are known to exhibit very low interfacial tensions [1]. We have worked on the mixture watertoluene-sodium dodecyl sulfate (SDS)-butanol whose phase diagram has been extensively studied by P. Lalanne, A. M. Bellocq and co-workers [5].

The interfacial tensions are expected to be related to the structure of the microemulsions in the bulk phases [6]. In order to investigate this point, we have completed the interfaces study with measurements of several properties of these microemulsions : viscosity, diffusion coefficient (from bulk light scattering techniques) and electrical conductivity.
2. Composition of the samples. - We have reported on table I the weight composition of the mixture. When water salinity varies, the mixture separates into two- or three-phases as indicated in table II. All the measurements have been done at the temperature $20 \pm 0.1{ }^{\circ} \mathrm{C}$. We have studied the system in the range $4 \%-10 \%$ of water salinities $S$. From 4 to $5.8 \%$ the lower phase is an oil in water micro-

Table I. - Weight composition of the mixtures.

$\begin{array}{lr}\text { Salt water } & 47.95 \% \\ \text { Toluene } & 46.35 \% \\ \text { SDS } & 1.95 \% \\ \text { Butanol 1 } & 3.75 \%\end{array}$

Table II. - Number and nature of the phases in equilibrium as a function of salinity.

\begin{tabular}{|l|l|l|}
\hline \multicolumn{1}{|c|}{ 2-phases } & \multicolumn{1}{|c|}{ 3-phases } & 2-phases \\
\hline Oil rich phase & Oil rich phase & $\begin{array}{c}\text { Water in oil } \\
\text { microemulsion }\end{array}$ \\
\cline { 2 - 2 } $\begin{array}{c}\text { Oil in water } \\
\text { microemulsion }\end{array}$ & $\begin{array}{c}\text { Microemulsion } \\
\text { (inversion zone) }\end{array}$ & Aqueous phase \\
\cline { 2 - 3 } & Aqueous phase & $S$ \\
\hline
\end{tabular}


emulsion and above $7.8 \%$ the upper phase a water in oil microemulsion [5]. Between $5.8 \%$ and $7.8 \%$, limits of the three-phase domain, the middle phase seems to be a concentrated microemulsion and around $7 \%$ to exhibit an inversion between oil in water and water in oil structures.

3. Viscosity measurements. - The interpretation of surface light scattering experiments requires the knowledge of the bulk phase viscosity. This has been achieved by using a capillary viscosimeter and by measuring independently the density of the phases. The results are shown on figure 1 .

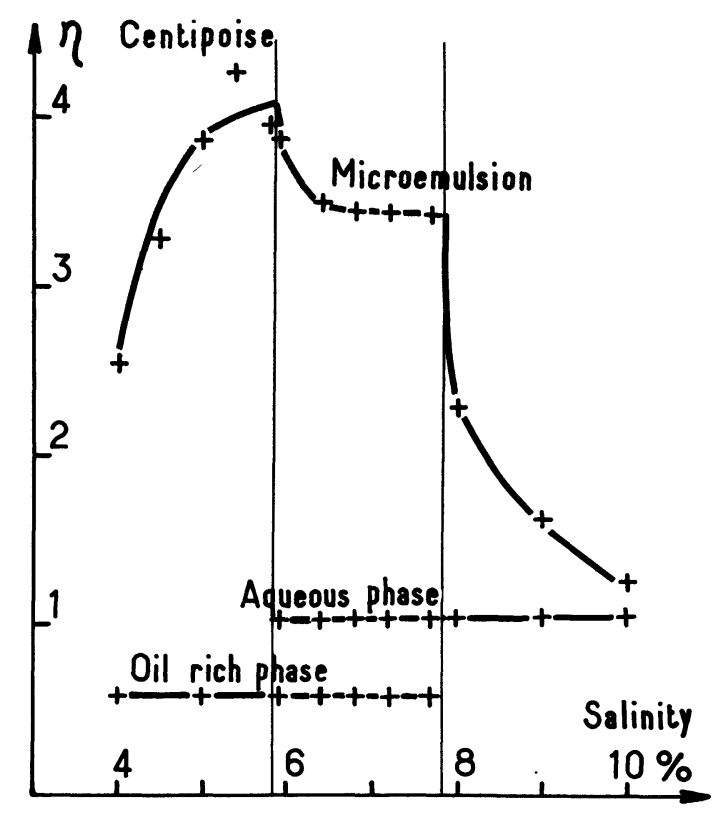

Fig. 1. - Viscosity of the bulk phases versus salinity.

4. Interfacial tension measurements. - The spontaneous thermally excited capillary waves at an interface between two fluids can be studied by inelastic light scattering [3]. These waves are overdamped at a low interfacial tension oil-water interface. The interface is drawn back to its flat equilibrium position by restoring forces due to interfacial tension $\gamma$ and gravity. The waves are damped due to the viscosities $\eta$ and $\eta^{\prime}$ of the bulk phases below and above the surface. The spectrum of the light scattered by surface waves of wave vector $\mathbf{q}$ is Lorentzian and has a width [3] :

$$
\Delta v_{0}=\frac{\left(\gamma+\Delta \rho g / q^{2}\right) q}{4 \pi\left(\eta+\eta^{\prime}\right)}
$$

$\Delta \rho$ is the density difference between bulk phases. The term $\Delta \rho g / q^{2}$ is generally small compared to $\gamma$ in our experiments. The measurements of $\Delta v_{0}, \Delta \rho$ and of the viscosities $\eta$ and $\eta^{\prime}$ allow $\gamma$ to be determined.
The intensity of the scattered light is :

$$
I=\frac{k T}{\gamma q^{2}+\Delta \rho g} F\left(i, n_{\mathrm{r}}, n_{\mathrm{i}}\right)
$$

$I$ depends on the amplitude of thermal fluctuations $k T /\left(\gamma q^{2}+\Delta \rho g\right)$ and on a geometrical factor $F$, function of $i$, incidence angle, $n_{\mathrm{i}}$ and $n_{\mathrm{r}}$ refractive indices of the phases crossed by the incident and refracted beams.

We see for this expression that the scattered intensity is large if the interfacial tension is small and if the wave vector $\mathbf{q}$ is also small : this corresponds to a small scattering angle.

The variation of $F$ is represented on figure 2 as a function of $i$ for a given choice of typical values for $n_{\mathrm{i}}$ and $n_{\mathrm{r}}$. For a given $\mathbf{q}, I$ presents a strong maximum at the limit incidence $\left(n_{\mathrm{i}}>n_{\mathrm{r}}\right)$. When $i$ approaches $\pi / 2$, the scattered intensity goes to zero.

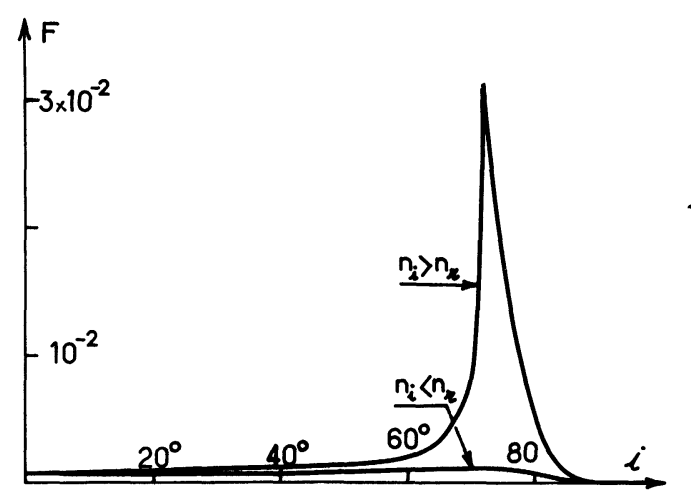

Fig. 2. - Variation of $F$ versus incidence angle $i$, and refractive indices : $n_{\mathrm{i}}=1.43, n_{\mathrm{r}}=1.352$ and $n_{\mathrm{i}}=1.352, n_{\mathrm{r}}=1.43$.

The experimental set-up is represented on figure 3 . The spectrum analysis of the scattered light is made by optical beating. The mixing can be homodyne or heterodyne depending on the local oscillator strength. In the present experiments, the local oscillator is the light scattered by small optical defects of the scattering cell. As its intensity $I_{0}$ can be hardly modified, we vary the ratio $I / I_{0}$ by changing the incidence angle.

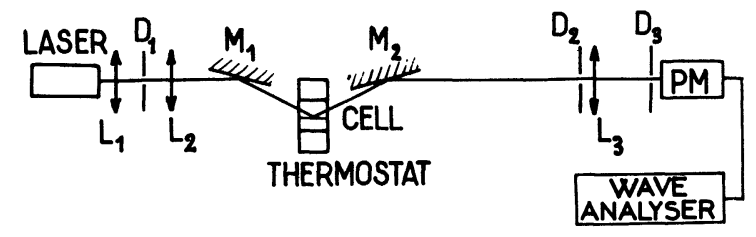

Fig. 3. - Experimental set-up.

Figure $4 a$ shows a typical spectrum and figure $4 b$ the variation of spectral width versus $i$. Refractive indices of this sample (salinity $6.8 \%$ ) are

$$
n_{\mathrm{r}}=1.4966 \text { and } n_{\mathrm{i}}=1.4294 \text {. }
$$




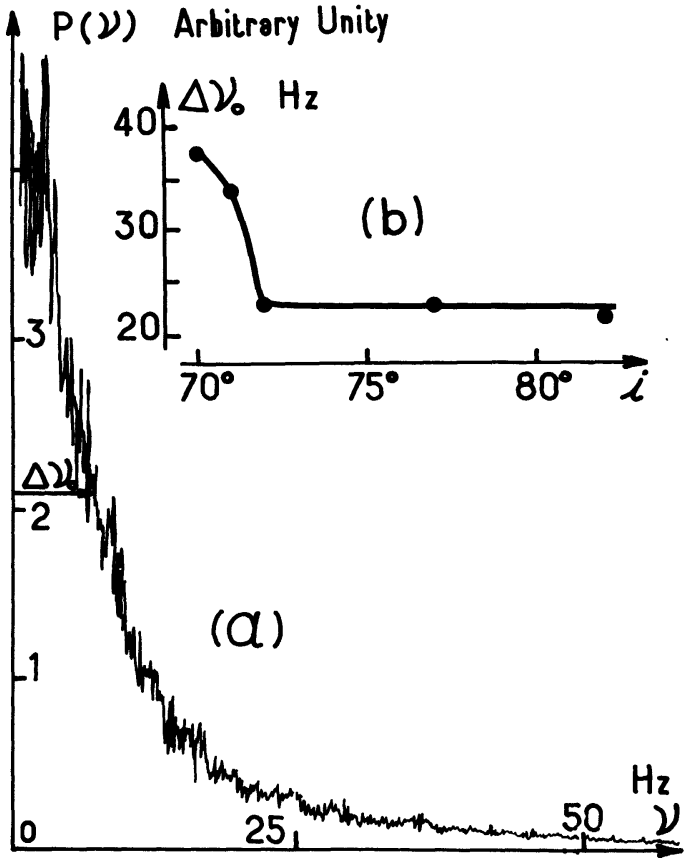

Fig. 4. - a) Typical spectrum $\left.q=688 \mathrm{~cm}^{-1}, i=82^{\circ} ; b\right)$ Spectral width versus incidence angle for the same interface and the same wave vector. Sample salinity is $6.8 \%$.

The scattered intensity is maximum for $i=69.5^{\circ}$. For $i \lesssim 72^{\circ}, \Delta v$ is not constant indicating that the detection is mixed homodyne and heterodyne. For $i>72^{\circ}, \Delta v$ remains constant, the detection is heterodyne and $\Delta v=\Delta v_{0}$. From this value and the viscosity and density measurements described in paragraph 1 , we deduce $\gamma$ by using equation (1). The results are reported on figure 5 .

We have verified that the dispersion law $\left(\Delta v_{0}\right.$ versus $q$ ) of the surface waves was in agreement with

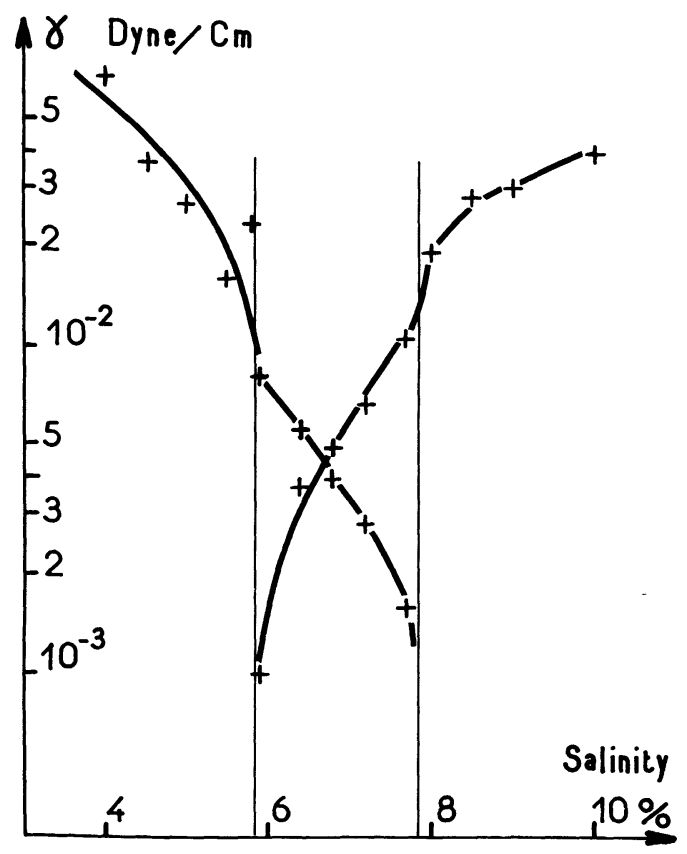

Fig. 5. - Interfacial tension variation versus salinity. equation (1). A departure from this relation could indicate the existence of a transversal surface viscosity [4] which is negligible in the present experiments $\left({ }^{1}\right)$.

The lowest interfacial tensions are indeed observed in the three-phase domain. The interfacial tension varies rapidly when crossing the limit between twophase and three-phase domains.

5. Diffusion coefficient of microemulsion phases. The diffusion coefficient of microemulsion phases has been deduced from the autocorrelation function of the scattered light [7].

The temporal relaxation of thermal micelle concentration fluctuations is exponential $\left({ }^{2}\right)$ excepted close to the limit between two-phase and three-phase domains. In these last cases, the microemulsion turbidity is large and we observe some multiple scattering. As it is difficult to estimate the proportion of light scattered two or more times, the diffusion coefficients that we have deduced show large error bars. Figure 6 represents all the results. The diffusion coefficient is small close to the two-phase and threephase transition. The decrease of the diffusion coefficient in these regions can be explained either by an increase in micellar sizes or by interactions between

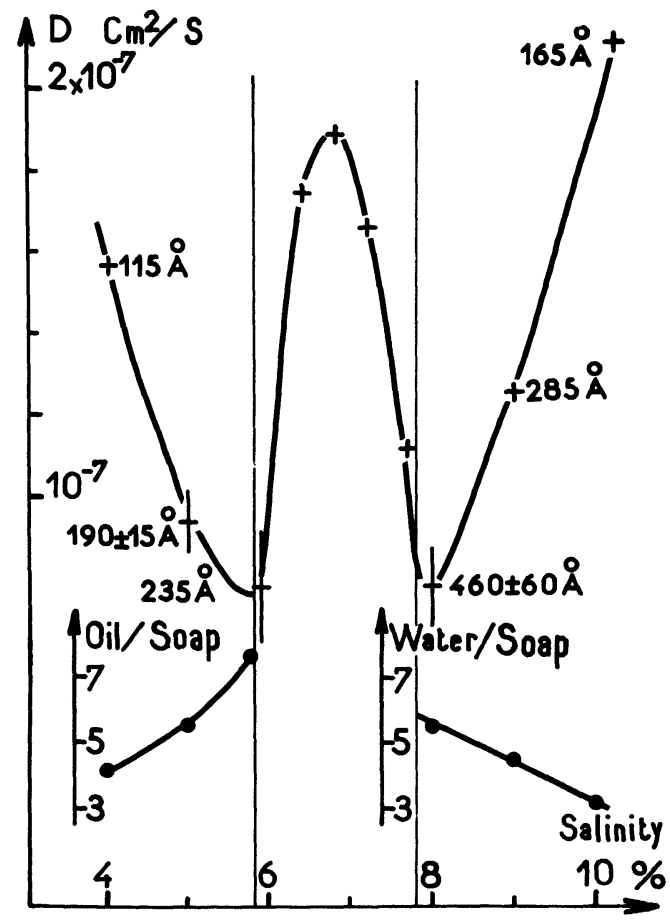

Fig. 6. - Variation with salinity of : - diffusion coefficient ; - - - - oil to soap ratio ; - - _. - water to soap ratio. The measurements are relative to microemulsion phases.

( $\left.{ }^{1}\right)$ In a former paper [4], we reported that for the same system the variation of $\Delta v_{0}$ versus $q$ in some cases did not follow equation (1). In fact this was for a case of mixed homodyne and heterodyne detection where equation (1) is not valid.

$\left({ }^{2}\right)$ The polydispersity of the micellar sizes used in these systems is small [7]. A deviation from an exponential behaviour of the autocorrelation function becomes observable only for large dispersities. 
micelles [7]. The diffusion coefficient behaviour of oil in salt water microemulsions seems to indicate that interaction effects are negligible [8]. The observed diffusion coefficient decrease in the left two-phase domain $(S<5.8 \%$ is probably due to micellar size variations. Neglecting the interactions, we have calculated these sizes from :

$$
D=\frac{k T}{6 \pi \eta R} .
$$

We find $R=115 \AA$ at $S=4 \%$ and $R=235 \AA$ at $5.8 \%$. The micellar volume varies as $R^{3}$, and its surface as $R^{2}$. It is reasonable to assume that all the soap molecules are around the micelle and that the ratio of oil to soap varies as $R$. In this way, we neglect the role of interfacial alcohol, but the argument should give a good first approximation. Figure 6 shows the variation of the ratio of oil to soap versus $S$ below $5.8 \%$. It changes by a factor 2 between $S=4 \%$ and $5.8 \%$. As $R$ changes also by a factor 2 , the interpretation seems satisfactory.

In the right two-phase domain : $S>7 \%$, the micelles have a water core and the continuous phase contains the oil. The micellar volume fraction is important : 15 to $20 \%$. The diffusion coefficient of water in oil microemulsions exhibits a minimum around a volume fraction of $10 \%$ for micelles of constant size [7]. The variation observed on figure 6 is certainly not due entirely to micellar size variation, but we were not able to separe the contribution of size variations from those of interactions. However we estimated the apparent sizes of micelles from equation (3) and found $R=165 \AA$ at $S=10 \%$ and $R=460 \pm 60 \AA$ at $8 \%$. Let us note that the ratio of soap to water varies only by a factor of 2 within the same limits.

In the three-phase region, the middle phase seems to show an inversion between oil in water to water in oil microemulsion structure at $S=6.8 \%$. The diffusion coefficient passes through a maximum (Fig. 6). Let us recall that this behaviour has already been observed on microemulsions in which micelles have a constant composition at least in the oil in water side [7].

6. Electrical conductivity measurements. - We have measured the electrical conductivity of microemulsion phases. The results are reported on figure 7.

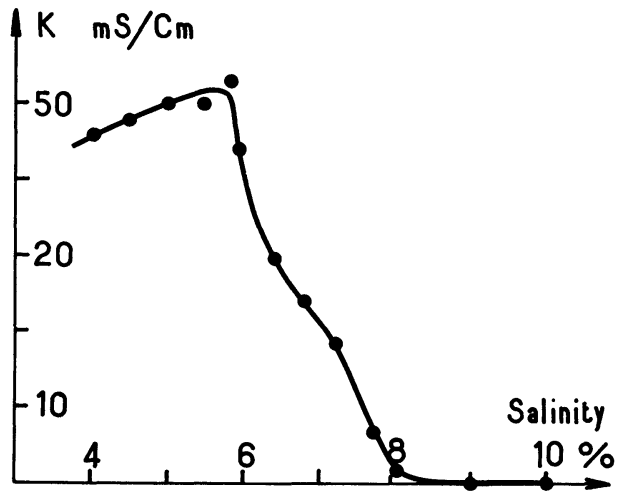

Fig. 7. - Microemulsion phase conductivity versus salinity.

No anomaly is observed at the transition between two-phase and three-phase domains.

When the amount of water in the microemulsion is large (low $S$, Fig. 7), the conductivity is large, due to the existence of continuous water paths from one electrode to the other : the continuous phase is then salt water. On the contrary, when the amount of water is small (large $S$ ), the continuous phase is organic and the conductivity is small.

7. Conclusion. - We have carried out both bulk and interfacial studies of an oil-water system in order to relate the surface properties to the bulk properties of microemulsion phases.

The study of the spectrum of the light scattered by thermal fluctuations at the interfaces allowed us to measure very low interfacial tensions without perturbing the systems. We plan now to compare this method to the spinning drop technique.

We also plan to measure interfacial thicknesses by studying the interface reflectivity variation with optical wavelength. We hope to achieve a better understanding of the physico-chemical processes responsible for the existence of low interfacial tensions by relating interfacial tensions, interfacial thicknesses and microemulsion bulk properties.

Acknowledgments. - We are greatly indebted to P. Lalanne for his help during the sample preparation and for much useful advice. We gratefully thank A. M. Bellocq for many helpful discussions.

\section{References}

[1] Healy, R. N., Reed, R. L., Stenmark, D. G., Soc. Pet. Eng. J. (1976) 147.

[2] Puig, J. E., Franses, E. I., Davis, H. T., Miller, W. G., SCRIVEN, L. E., Soc. Pet. Eng. J. 71 (1979).

[3] Langevin, D., Meunier, J. in Photon Correlation Spectroscopy and Velocimetry (Plenum Press) 1976.

[4] Cazabat, A. M., Langevin, D., Meunier, J., Pouchelon, A., Proceedings of the III International Conference on Colloid and Surface Science, Stockholm (1979) (to be published by Plenum Press).
[5] Belloce, A. M., Biais, J., Clin, B., Lalanne, P., LemanCEAU, B., J. Colloid Int. Sci. 70 (1979) 524.

[6] Miller, C. A., Hwan, R., Benton, W. J., ForT, T., J. Colloid Int. Sci. 61 (1977) 554.

[7] Cazabat, A. M., Langevin, D., Pouchelon, A., J. Colloid Int. Sci. 73 (1980) 1.

[8] Graciaa, A., Lachaise, J., Chabrat, P., Letamendia, L., Rouch, J., Vaucamps, C., J. Physique Lett. 39 (1978) L-235. 